\title{
Effects of Multiwalled Carbon Nanotube Surface Modification and Purification on Bovine Serum Albumin Binding and Biological Responses
}

\author{
Wei Bai, ${ }^{1}$ Zheqiong Wu, ${ }^{2}$ Somenath Mitra, ${ }^{2}$ and Jared M. Brown ${ }^{1}$ \\ ${ }^{1}$ Department of Pharmaceutical Sciences, Skaggs School of Pharmacy and Pharmaceutical Sciences, \\ University of Colorado-Anschutz Medical Campus, Aurora, CO 80045, USA \\ ${ }^{2}$ Department of Chemistry and Environmental Science, New Jersey Institute of Technology, Newark, NJ 07102, USA \\ Correspondence should be addressed to Jared M. Brown; jared.brown@ucdenver.edu
}

Received 18 May 2016; Revised 29 August 2016; Accepted 5 September 2016

Academic Editor: Andrew R. Barron

Copyright (C) 2016 Wei Bai et al. This is an open access article distributed under the Creative Commons Attribution License, which permits unrestricted use, distribution, and reproduction in any medium, provided the original work is properly cited.

\begin{abstract}
Carboxylation of multiwalled carbon nanotubes (MWCNTs) has been used to improve solubility in aqueous systems and for further functionalization with biologically active moieties for biomedical uses. An important consideration is that oxidation debris is generated during the process of carboxylation, which can be removed by base washing. We hypothesized that surface modification as well as purification by debris removal may alter physicochemical properties of MWCNTs and their ability to bind proteins. We utilized pristine MWCNT, carboxylated MWCNTs (F-MWCNTs), and base-washed carboxylated MWCNTs (BWF-MWCNTs) to examine formation of a bovine serum albumin (BSA) protein corona and impact on biological responses. We found that carboxylation increased the capability of F-MWCNTs to bind BSA, and base washing further increased this binding. Functionalization increased cellular uptake by rat aortic endothelial cells (RAEC) and mouse macrophages (RAW264.7), while base washing showed results similar to the functionalized analog. Interestingly, BSA binding downregulated mRNA levels of interleukin6 (IL-6) and heme oxygenase 1 (Hmoxl) in RAEC cells but upregulated the expression of IL-6 and Hmoxl in RAW264.7 cells. Overall, our study demonstrated that surface modification as well as further purification impacted the interaction of MWCNTs with proteins and subsequent cellular responses.
\end{abstract}

\section{Introduction}

Due to their unique mechanical, thermal, chemical, and electronic properties, carbon nanotubes (CNTs) have attracted a lot of attention in the field of nanotechnology. Most interestingly, the potential diagnostic and therapeutic applications of CNTs in medicine are being increasingly explored [16]. It is well known that nanoparticles are rapidly coated with various proteins in biological fluids (such as blood, plasma, or interstitial fluid) to form a protein corona $[7,8]$. Upon formation, the nanoparticle-protein corona complex, rather than the pristine nanoparticles per se, functions as the biological entity further interacting with other components inside cells or living organisms, which potentially influence the downstream biological events.

Recent studies have identified various proteins that can be adsorbed to different nanoparticles to form the protein corona. Among these, bovine serum albumin (BSA) has been commonly adopted as a model protein to study the formation of protein corona on nanoparticles, including carbon-based nanoparticles [9-12], metal nanoparticles such as gold [13-15], aluminum nanoparticles [16], and zinc oxide nanoparticles $[17,18]$. Nonetheless, the mechanisms underlying the interaction between nanoparticles and proteins and subsequent biological responses are still poorly understood.

The formation of a protein corona is hypothesized to highly depend on surface properties of nanoparticles. As for CNTs, surface functionalization has been developed to improve their dispersion, stability, and biocompatibility by introducing carboxylic groups or other oxygen-containing groups $[19,20]$. Carboxylated CNTs can further conjugate covalently with various functional molecules such as drugs, proteins, and oligonucleotides. For example, both singlewalled CNTs (SWCNTs) and multiwalled CNTs (MWCNTs) 
were functionalized using microwave-assisted acid treatment to induce carboxylation $[21,22]$ and were found to bind more proteins than pristine CNTs in simulated cell culture conditions [23]. On the other hand, acid oxidation of carbon nanotubes was reported to generate byproducts such as oxidation debris comprising of highly oxygenated polycyclic aromatic compounds and tube fragments which could potentially coat the nanotubes and alter physicochemical properties [24-26]. Oxidation debris was found to affect the dimension of CNTs and their surface properties, especially the number of free carboxylic groups on the surface [24, 2729], which possibly influences the formation of a protein corona on the MWCNTs. Oxidation debris could be removed after washing with dilute aqueous base $(0.01 \mathrm{M} \mathrm{NaOH})$ by converting the acidic groups to their dissolvable conjugate salts [24, 27]. This removal of oxidative debris has been reported to produce carbon nanotubes with a clean surface, which is an important consideration in nanomedicine [28, 30]. These studies raise the questions about possible impact of base washing on surface properties of carboxylated CNTs, as well as the subsequent influence on protein binding and biological response.

In this study, we utilized pristine MWCNT (MWCNTs), carboxylated MWCNTs (F-MWCNTs), and base-washed MWCNTs (BW-F-MWCNT) to study the binding of BSA and its subsequent effect on cellular responses in endothelial and macrophage cell types. As will be shown, we found that carboxylation increased the capability of MWCNTs to bind BSA. The binding was further increased by base washing because it provided a cleaner surface and more active sites. Further, cellular uptake by endothelial cells and macrophages was increased with carboxylation and base washing. Consequently we believe base washing is an important consideration in applications such as drug delivery. Lastly, though these surface modifications had no impact on cell viability, interleukin-6 (IL-6) and heme oxygenase 1 (Hmoxl) expression in RAEC and macrophages were altered in a cell dependent manner.

\section{Materials and Methods}

2.1. Carboxylation and Base Washing of Pristine MWCNTs. Pristine MWCNTs $(0.5-2 \mu \mathrm{m}$ in length and $30-50 \mathrm{~nm}$ in diameter) were purchased from Cheaptubes Inc. (Cambridgeport, VT, USA). The carboxylation of pristine MWCNTs was carried out using a microwave accelerated reaction system according to previously published methods [31]. Briefly, a preweighed amount of pristine MWCNTs was added to reaction chamber together with a mixture of concentrated $1: 1 \mathrm{H}_{2} \mathrm{SO}_{4}(95 \%-98 \%)$ and $\mathrm{HNO}_{3}$ (70\%). The reaction vessels were subject to microwave radiation at a preset temperature of $140^{\circ} \mathrm{C}$ for $20 \mathrm{~min}$. After cooling to room temperature, the product was vacuum filtered using Milli-Q water with $10 \mu \mathrm{m}$ pore size filter paper, until the filtrate reached a neutral $\mathrm{pH}$. The product was dried in a vacuum oven at $70^{\circ} \mathrm{C}$ until reaching a constant weight and was referred to as carboxylated functionalized MWCNTs (FMWCNTs).
To remove the oxidation debris, F-MWCNTs were washed with $0.01 \mathrm{M} \mathrm{NaOH}$ until the filtrate turned from brown to colorless. The resulting product was washed with Milli-Q water until a neutral $\mathrm{pH}$ was obtained. Finally, the product was washed by $0.01 \mathrm{M} \mathrm{HCl}$ and then washed with Milli-Q water to neutral $\mathrm{pH}$ again. The base-washed sample was referred to BW-F-MWCNTs. All MWCNTs were characterized using a scanning electron microscope (SEM, LEO $1530 \mathrm{VP}$ ) equipped with an energy-dispersive X-ray analyzer (EDX), and the diameter and length were measured based on fifty individual nanotubes. The elemental compositions of MWCNTs were determined using Fourier Transform Infrared spectroscopy (FTIR) (Perkin-Elmer). To measure maximum solubility of F-MWCNTs and BW-F-MWCNTs in water, saturated solutions were prepared and allowed to settle for 24 hours, and the saturated solution was decanted and dried until constant weight to measure solubility.

2.2. Formation of BSA Protein Corona on MWCNTs. MWCNTs were suspended in deionized water at $1 \mathrm{mg} / \mathrm{mL}$ and sonicated for $2 \mathrm{~min}$ in a cup horn sonicator. MWCNTs were used immediately following sonication to minimize any settling of the suspension. Bovine serum albumin (BSA) was purchased from Sigma and dissolved in PBS at $1 \mathrm{mg} / \mathrm{mL}$. To generate a protein corona, $200 \mu \mathrm{L}$ of MWCNT $(1 \mathrm{mg} / \mathrm{mL})$, $500 \mu \mathrm{L}$ of BSA solution $(1 \mathrm{mg} / \mathrm{mL})$, and $700 \mu \mathrm{L}$ of distilled water were mixed and incubated on a rotator overnight at $4^{\circ} \mathrm{C}$. The mixture was centrifuged $\left(14,000 \mathrm{rpm}, 10 \mathrm{~min}, 4^{\circ} \mathrm{C}\right)$ and the pellets were washed twice to remove nonadsorbed BSA and were resuspended in water at $1 \mathrm{mg} / \mathrm{mL}$. To quantify the amount of BSA bound to MWCNTs, the concentration of BSA in the supernatant collected above was determined using the Pierce BCA protein assay. The amount of BSA bound to MWCNTs was calculated by subtracting the protein concentration in the supernatant from the initial protein concentration in the mixture. We did not measure the protein concentration in the presence of MWCNTs based on the influence of MWCNTs themselves on absorbance measurements at $562 \mathrm{~nm}$. The binding of BSA to MWCNTs was also confirmed by SDS-PAGE (sodium dodecyl sulfate polyacrylamide gel electrophoresis). An equal volume of MWCNT complex and staining buffer was mixed and loaded into the wells of a $8 \%$ gel (Thermo Fisher Scientific). The gel was stained with Coomassie blue. A SeeBlue prestained protein standard (Thermo Fisher Scientific) was used to identify the presence of BSA on MWCNTs. In addition, UV-vis spectra of $50 \mu \mathrm{g} / \mathrm{mL}$ MWCNTs with or without BSA protein corona were measured using a NanoDrop 2000c. The hydrodynamic size and zeta potential of MWCNTs were determined using a Zetasizer Nano ZS (Malvern Instruments Inc., Massachusetts, USA). To measure the hydrodynamic size of MWCNTs, we immediately prepared $50 \mu \mathrm{g} / \mathrm{mL}$ MWCNTs by diluting the $1 \mathrm{mg} / \mathrm{mL}$ solution with water. Immediately after sonication to minimize settling, we added $1 \mathrm{~mL}$ MWCNT suspension into a cuvette and measured the hydrodynamic size. These measurements were conducted three times.

2.3. Cell Lines. The macrophage-like murine cell line RAW264.7 (ATCC, Manassas VA, USA) was cultured in 
TABLE 1: Characterization of MWCNTs.

\begin{tabular}{lccccccc}
\hline \multirow{2}{*}{ Samples } & \multicolumn{4}{c}{ Elemental composition (\% weight) } & Diameter (nm) & Length (nm) & \multirow{2}{*}{ Solubility (mg/mL) } \\
& $\mathrm{C}$ & $\mathrm{O}$ & $\mathrm{Fe}$ & $\mathrm{Ni}$ & & & \\
\hline MWCNTs & 95.54 & 3.47 & 0.53 & 0.46 & $34 \pm 9$ & $1205 \pm 360$ & - \\
F-MWCNTs & 86.38 & 13.62 & - & - & $35 \pm 11$ & $767 \pm 525$ & 1.51 \\
BW-F-MWCNTs & 93.36 & 6.64 & - & - & $35 \pm 7$ & $737 \pm 457$ & 2.25 \\
\hline
\end{tabular}

Dulbecco's Modified Eagle's Medium (DMEM) supplemented with $10 \%$ fatal bovine serum (FBS) and $1 \%$ penicillin/ streptomycin. The cells were incubated in a humidified incubator at $37^{\circ} \mathrm{C}$ in $5 \% \mathrm{CO}_{2}$. Rat aortic endothelial cells (RAEC) were cultured in rat endothelial cell growth media (Cell Applications Inc., San Diego, CA, USA) in a humidified incubator at $37^{\circ} \mathrm{C}$ in $5 \% \mathrm{CO}_{2}$.

2.4. Cellular Uptake of MWCNTs. We investigated the cellular uptake of MWCNTs with or without BSA coating by utilizing flow cytometry (Accuri ${ }^{\mathrm{TM}}$ C6, BD Biosciences, Ann Arbor, MI) based on an increase in side scatter intensity (SSC) that is proportional to cell granularity [32]. Briefly, cells were plated and allowed to reach $80 \%$ confluency. The cells were then exposed to $50 \mu \mathrm{g} / \mathrm{mL}$ MWCNTs with and without BSA coating in serum-free medium (DMEM/F-12). The use of serum-free medium is to prevent the additional binding of proteins in the serum to either uncoated MWCNTs or BSA-coated MWCNTs. After treatment for 24 hours, the cells were washed with the phosphate-buffered saline (PBS) and detached using $0.025 \%$ trypsin-EDTA. The cells were then analyzed for increases in side scatter shift as compared to the untreated cells. The experiments were repeated at least three times.

We also confirmed the uptake of MWCNTs with and without BSA coating by cells using enhanced darkfield microscopy (Cytoviva Inc., Auburn, AL). Briefly, the cells were plated in a chamber slide and allowed to grow for one day in the complete medium. The cells were then treated with $50 \mu \mathrm{g} / \mathrm{mL}$ MWCNTs with and without BSA coating for 24 hours in serum-free medium. Following treatment, the cells were washed with phosphate-buffered saline (PBS) and fixed with $4 \%$ paraformaldehyde for $10 \mathrm{~min}$ at room temperature. The nuclei were stained with DAPI. The cells were imaged using enhanced darkfield microscopy (Cytoviva, Inc., Auburn, AL, USA).

2.5. Cell Viability and Gene Expression. RAW264.7 and RAEC cells were plated and allowed to reach $80 \%$ confluency. The cells were exposed to $50 \mu \mathrm{g} / \mathrm{mL}$ MWCNTs with and without BSA coating in serum-free medium (DMEM/F-12) for 24 hours. Cell viability was performed using the MTS assay (CellTiter 96, Promega) according to the manufacture's protocol. Briefly, MWCNT suspensions were aspirated after treatment, followed by three washes with PBS, and then the MTS reagents were added into the wells. After incubation for $30 \mathrm{~min}$, the plates were centrifuged (1200 rpm, $5 \mathrm{~min}$ ) and the supernatants were transferred into a new 96-well plate, which is subject to measurement of the formazan absorbance at $490 \mathrm{~nm}$ [33]. For quantitative real-time PCR, total RNA was isolated using Direct-zol RNA MiniPrep (Zymo Research Corp., Irvine, CA) according to the manufacturer's instruction, and total RNA (1-2 $\mu \mathrm{g})$ was transcribed to cDNA using an iScript cDNA synthesis kit (Bio-Rad Laboratories, Inc., Hercules, CA), and mRNA expression of interleukin-6 (IL6) and heme oxygenase 1 (Hmoxl) were determined using SsoAdvanced ${ }^{\mathrm{TM}}$ SYBR green supermix (Bio-Rad Laboratories, Inc., Hercules, CA) and QuantiTect primer (Qiagen, Valencia, CA). The relative mRNA levels were normalized to $\mathrm{GAPDH}$, as an internal reference, using $\Delta \Delta \mathrm{Ct}$ method. The experiments were repeated at least three times.

2.6. Statistical Analysis. All graphs and statistical analysis were performed using Prism 6 software (GraphPad, San Diego, CA). Statistical significance was analyzed by oneway analysis of variance (ANOVA) with differences between groups assessed using Dunnett's post hoc tests. Differences were considered statistically significant when $p<0.05$.

\section{Results}

3.1. Characterization of MWCNTs, F-MWCNTs, and BW-FMWCNTs. SEM analysis showed that MWCNTs remained intact with minimal visible tube defect after acid treatment (Figures 1(a)-1(c)). Elemental analysis showed that metal impurities in MWCNTs were iron and nickel, which were removed by carboxylation (Table 1 ). We also found that the percentage of oxygen in F-MWCNTs was much higher than pristine MWCNTs due to the generation of carboxylic groups. The oxygen content decreased by $51 \%$ after base washing, indicating the removal of over oxidized moieties. By removing impurities from the surface, more carboxylate groups were exposed in BW-F-MWCNTs, which led to an increase of the aqueous solubility from $1.51 \mathrm{mg} / \mathrm{mL}$ of FMWCNTs to $2.25 \mathrm{mg} / \mathrm{mL}$ of BW-F-MWCNTs. In contrast, pristine MWCNTs had poor solubility in water and settled out of the suspension. We found that carboxylation reduced the length of MWNCTs, possibly due to breakage of pristine MWCNTs at the defect sites. On the other hand, we did not find a difference in the diameter and length of FMWCNTs before and after base washing (Table 1), indicating that the microwave process did not fragment MWCNTs and cause excessive external tube damage. Carboxylation of MWCNTs was also confirmed by the FTIR spectra (Figure $1(\mathrm{~d})$ ), which showed $\mathrm{C}=\mathrm{O}$ stretching frequency at $1716 \mathrm{~cm}^{-1}$ and $\mathrm{C}-\mathrm{O}$ stretching vibration at $1227 \mathrm{~cm}^{-1}$, indicating the presence of carboxyl group in F-MWCNTs but not in pristine MWCNTs. We also observed $\mathrm{C}=\mathrm{C}$ stretching at $1576 \mathrm{~cm}^{-1}$ in all samples, which exists in the carbon skeleton. 


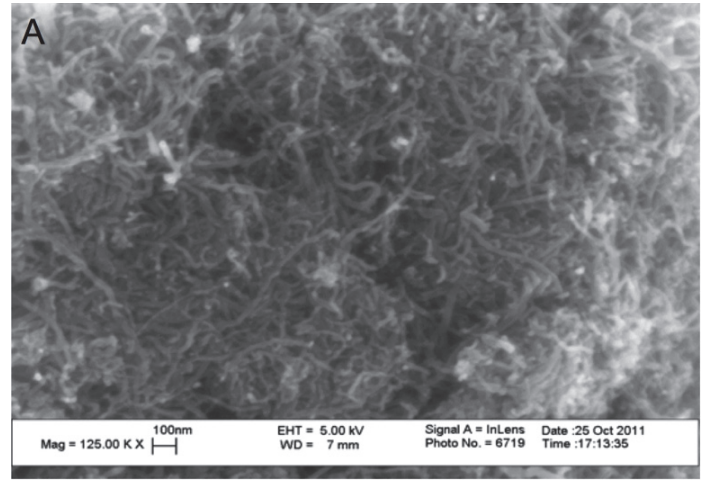

(a)

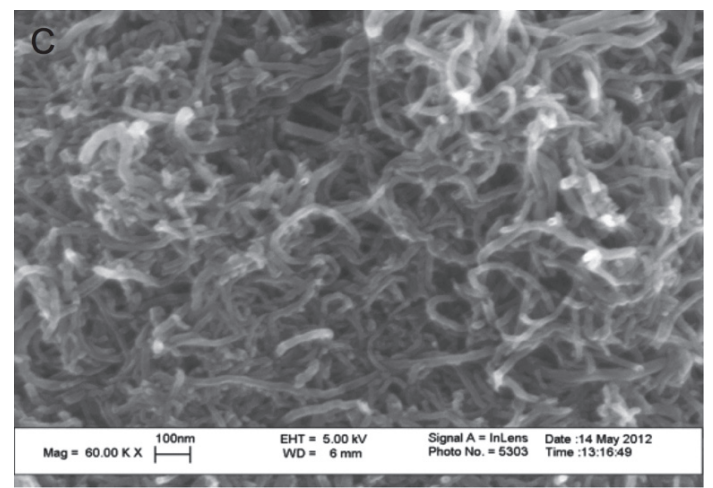

(c)

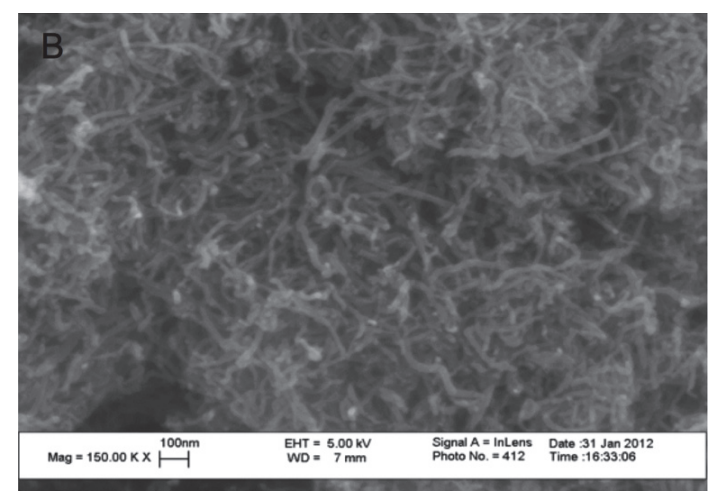

(b)
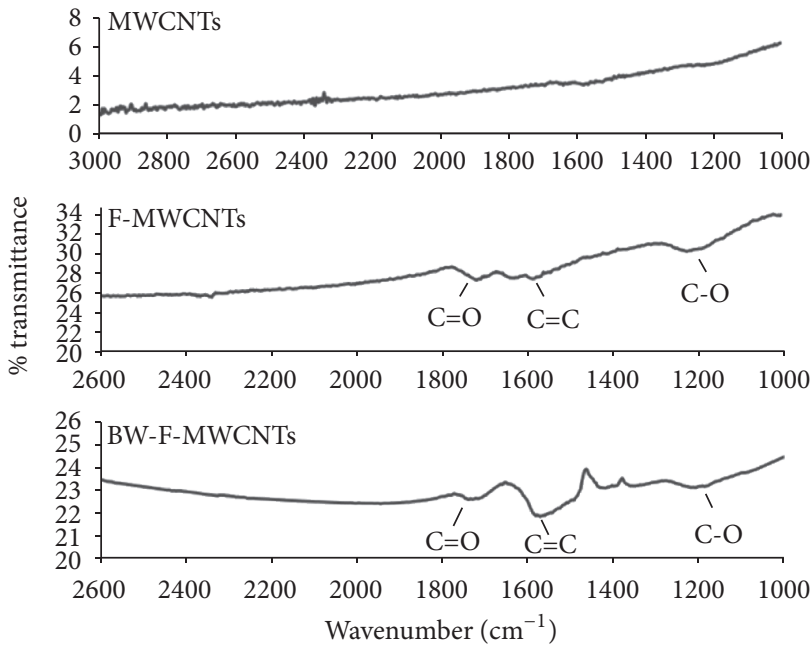

(d)

FIGURE 1: Characterization of MWCNTs. SEM image of all MWCNTs including (a) pristine MWCNT, (b) functionalized MWCNT, and (c) base-washed F-MWCNT. (d) FTIR spectra of MWCNT, F-MWCNT, and BW-F-MWCNT.

3.2. Effect of Surface Modification on the Ability of MWCNTs to Bind BSA. The amount of BSA bound to MWCNTs was quantified to be $139 \pm 12,230 \pm 56$, and $423 \pm 14 \mu \mathrm{g} / \mathrm{mL}$ for pristine MWCNTs, F-MWCNTs, and BW-F-MWCNTs, respectively (Figure 2(a)). The presence of BSA bound to MWCNTs was confirmed using SDS-PAGE (Figure 2(b)), further demonstrating that carboxylation increased the capacity of MWCNTs to bind BSA and base washing enhanced the BSA binding capacity of carboxylated F-MWCNTs. In addition, $\mathrm{UV}$-vis spectrometry also confirmed the binding of BSA to F-MWCNTs and BW-F-MWCNTs (Figures 2(d)-2(e)); however, this was not confirmed for pristine MWCNTs possibly due to aggregation of these particles.

The addition of BSA influenced the hydrodynamic size of MWCNTs (Table 2). Compared to the large hydrodynamic size of pristine MWCNTs $(1056 \pm 251 \mathrm{~nm})$, BSAcoated MWCNTs displayed a decreased hydrodynamic size $(573.3 \pm 16.9 \mathrm{~nm})$ by nearly $50 \%$ because the coating improved colloidal behavior. Interestingly, binding of BSA slightly increased the hydrodynamic size of F-MWCNTs from 234.1 $20.9 \mathrm{~nm}$ to $251.3 \pm 5.4 \mathrm{~nm}$, and the size of BW-F-MWCNTs from $215.8 \pm 26.9$ to $280.2 \pm 38.5 \mathrm{~nm}$. Lastly, binding of
BSA had no impact on zeta potential of the three forms of MWCNTs.

3.3. Effect of Surface Modification on Cellular Uptake of MWCNTs. The uptake of MWCNTs by either RAEC or RAW264.7 cells was determined using flow cytometry and darkfield imaging. The flow cytometry data, assessed by changes in side scatter, showed that RAEC internalized more F-MWCNTs and BW-F-MWCNTs than pristine MWCNTs, while there was no difference in cellular uptake between F-MWCNT and BW-F-MWCNT (Figure 3(a)), suggesting that base washing had no impact on the cellular uptake of F-MWCNTs. Furthermore, we did not find a difference in cellular uptake of MWCNTs after BSA coating, indicating that BSA coating does not influence the cellular uptake of MWCNTs (Figure 3(a)). Darkfield microscopy confirmed the internalization of MWCNTs by RAEC (Figure 3(c)).

Similarly, we found that RAW264.7 cells had greater cellular uptake of F-MWCNTs and BW-F-MWCNTs than pristine MWCNTs, and base washing did not influence the uptake of F-MWCNTs (Figure 3(b)). BSA coating also did not change the uptake of MWCNTs by RAW264.7 cells 


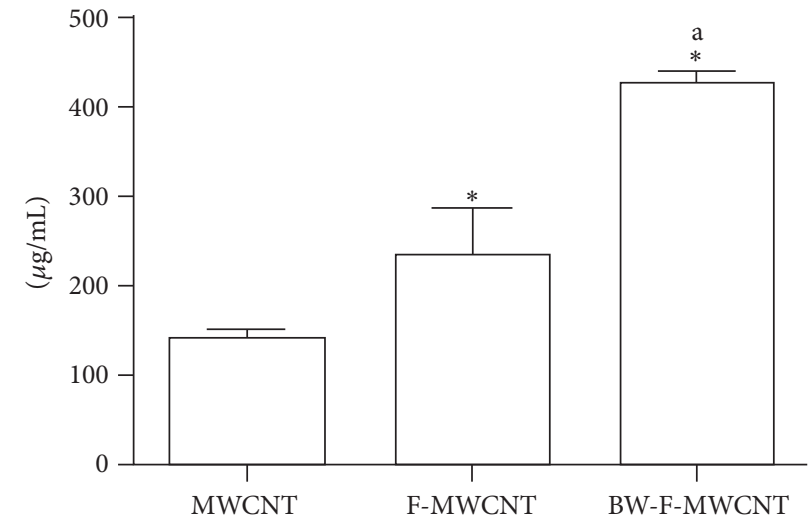

(a)

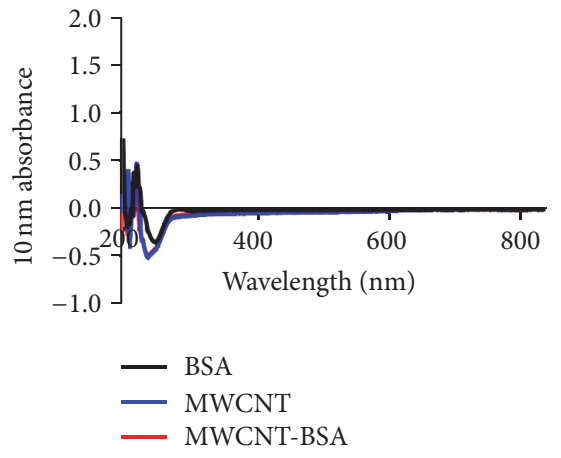

(c)

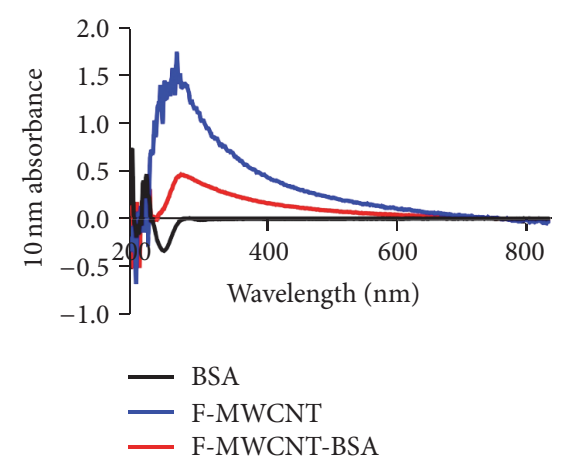

(d)

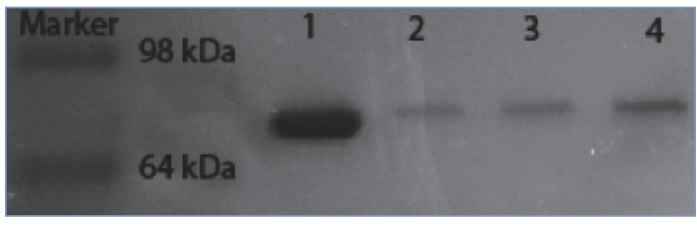

(b)

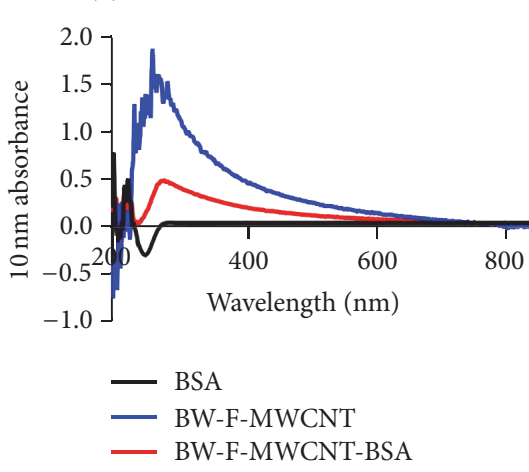

(e)

FIGURE 2: Confirmation of BSA bound to MWCNTs. (a) Quantification of BSA bound to MWCNT using a Pierce BCA protein assay; (b) SDS-PAGE image of BSA binding to MWCNTs. Lanes: 1, BSA alone; 2, BSA bound to pristine MWCNT; 3, BSA bound to F-MWCNT; 4, BSA bound to BW-F-MWCNT. (c-e) UV-vis spectral analysis of MWCNTs with and without BSA coating. In (a) ${ }^{*} p<0.05$, compared to the amount of BSA bound to MWCNT; ${ }^{a} p<0.05$, significant difference of the amount of BSA between F-MWCNT and BW-F-MWCNT.

TABLE 2: Effects of BSA coating on hydrodynamic size and zeta potential of MWCNTs in water.

\begin{tabular}{|c|c|c|c|c|}
\hline & \multicolumn{2}{|c|}{ Hydrodynamic size (nm) } & \multicolumn{2}{|c|}{ Zeta potential $(\mathrm{mV})$} \\
\hline & Uncoated & BSA-coated & Uncoated & BSA-coated \\
\hline MWCNT & $1056 \pm 251$ & $573.3 \pm 16.9^{*}$ & $-14.4 \pm 7.9$ & $-13.5 \pm 7.5$ \\
\hline F-MWCNT & $234.1 \pm 20.9$ & $251.3 \pm 5.4$ & $-37.7 \pm 5.3$ & $-41 \pm 4.2$ \\
\hline BW-F-MWCNT & $215.8 \pm 26.9$ & $280.2 \pm 38.5$ & $-42.6 \pm 1.3$ & $-39.2 \pm 1.3$ \\
\hline
\end{tabular}

${ }^{*} p<0.05$, comparison between uncoated and BSA-coated MWCNTs.

(Figure 3(b)). Again, darkfield microscopy confirmed the uptake of MWCNTs by RAW264.7 cells (Figure 3(d)).

3.4. Effect of MWCNT Surface Modification on Cellular Viability and Biological Responses. In order to investigate if surface modification affects the ability of MWCNTs to alter cell viability, RAEC and RAW264.7 cells were treated with pristine MWCNTs, F-MWCNTs, and BW-F-MWCNTs, as well as their BSA-coated counterparts. We found that surface modifications of MWCNTs had no impact on cell viability (Table 3). We also found that BSA binding did not influence the viability of either RAEC or RAW264.7 cells (Table 3 ).

In contrast to no effect on cellular viability, we found that surface modification of MWCNTs significantly affected biological responses in terms of gene expression of IL- 6 and Hmoxl in RAEC cells but not RAW264.7 cells. Compared
TABLE 3: Viability of RAEC and RAW264.7 exposed to MWCNT with and without BSA coating.

\begin{tabular}{lcccc}
\hline & \multicolumn{2}{c}{ RAEC } & \multicolumn{2}{c}{ RAW264.7 } \\
& Uncoated & BSA-coated & Uncoated & BSA-coated \\
\hline MWCNT & $95.6 \pm .8$ & $91.5 \pm 6.2$ & $106.4 \pm 6.8$ & $109.0 \pm 6.1$ \\
F-MWCNT & $93.0 \pm 5.6$ & $86.1 \pm 6.6$ & $108.4 \pm 7.5$ & $108.6 \pm 12.3$ \\
BW-F-MWCNT $95.9 \pm 6.2$ & $90.7 \pm 2.7$ & $107.0 \pm 7.8$ & $113.0 \pm 12.9$ \\
\hline
\end{tabular}

to pristine MWCNTs, F-MWCNTs and BW-F-MWCNTs increased the expression of IL-6 and Hmoxl mRNA in RAEC cells (Figures 4(a) and 4(b)). However, BSA binding significantly inhibited the mRNA expression of IL- 6 induced by uncoated MWCNTs but slightly decreased the mRNA expression of Hmoxl in RAEC cells (Figures 4(a) and 4(b)). 


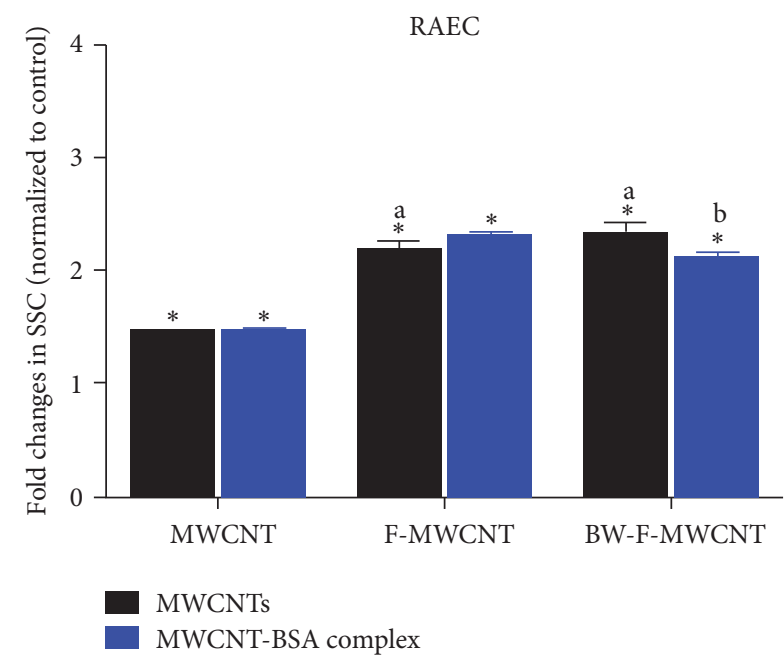

(a)

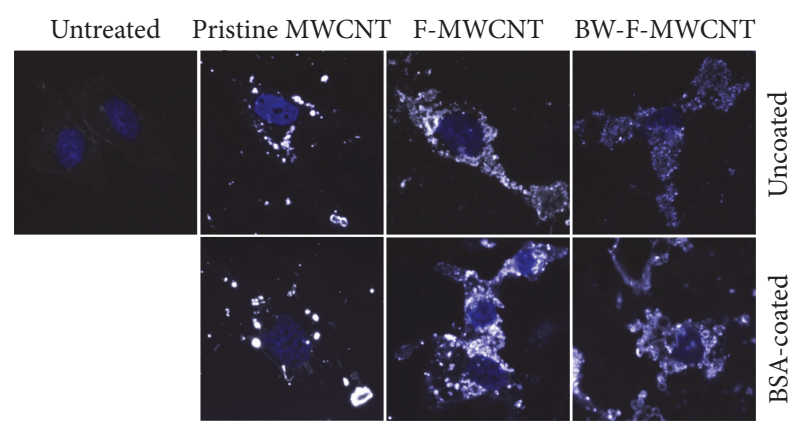

(c)

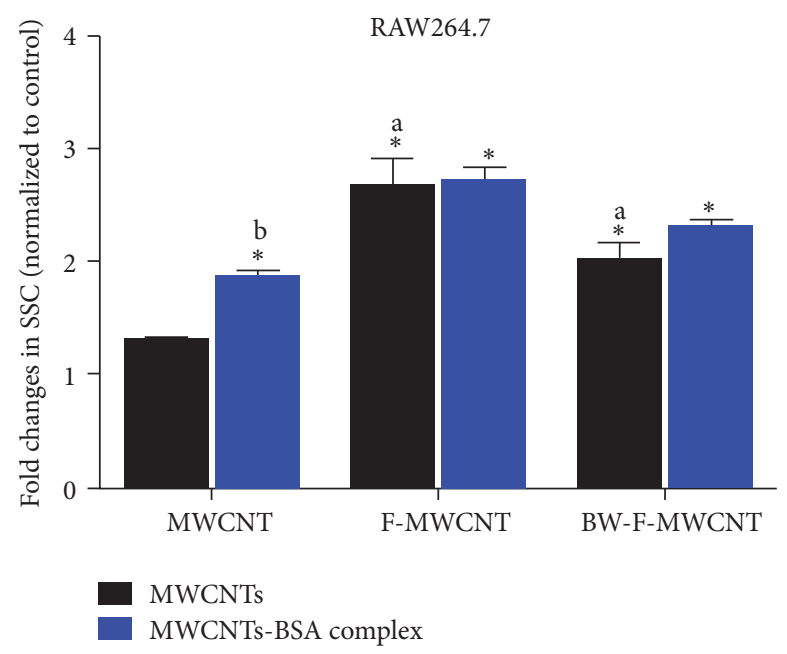

(b)

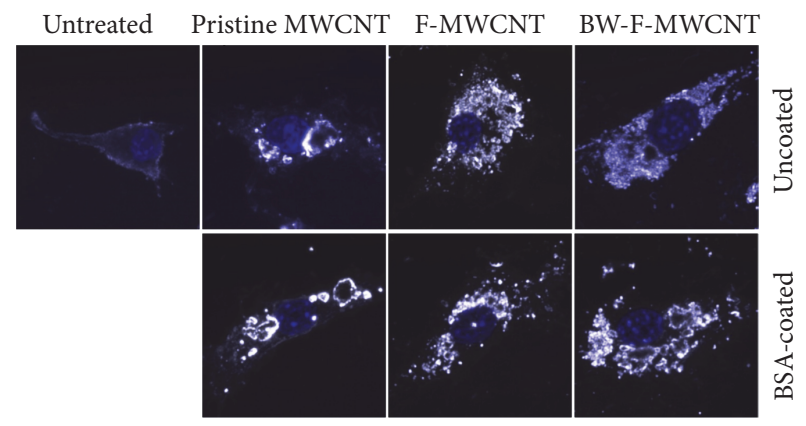

(d)

FIGURE 3: Uptake of MWCNTs with or without BSA coating by either RAEC cells or RAW264.7 cells. MWCNTs with or without BSA were internalized by RAEC cells (a) or RAW264.7 cells (b) measured by flow cytometry based on the changes in side scatter shift. The cellular uptake of MWCNTs with or without BSA coating was visualized using darkfield imaging, for RAEC cells (c) and RAW264.7 cells (d) (magnification: $100 \mathrm{x}) ;{ }^{*} p<0.05$, compared to the control; ${ }^{\mathrm{a}} p<0.05$, compared to MWCNT; ${ }^{\mathrm{b}} p<0.05$, comparison between MWCNTs with and that without BSA coating.

Interestingly, we found that carboxylation and base washing did not affect the ability of MWCNTs to alter the expression of IL- 6 and Hmoxl in RAW264.7 cells, but BSA binding remarkably increased the expression of IL-6 and Hmoxl mRNA (Figures 4(c) and 4(d)). We did not observe a difference in biological response to MWCNTs before and after base washing, suggesting that base washing does not influence the biological response of carboxylated MWCNTs.

\section{Discussion}

Carbon nanotubes are promising materials for many biomedical and pharmaceutical applications. In general, the pristine MWCNTs are intrinsically insoluble in water. In order to improve the solubility and biocompatibility, it is necessary to modify the surface of MWCNTs through chemical functionalization and other methods. Among these, carboxylation of MWCNTs is one of the widely used methods to improve the solubility in aqueous solution and further provide more reactive moieties. On the other hand, recent research has shown that acid oxidation of carbon nanotubes generates oxidation debris, which in turn influences the dimension and surface properties of CNTs [27-30] and these impurities could be washed with dilute aqueous base [24, 27]. However, it is still unclear whether base washing has an impact on biological properties of carboxylated MWCNTs, as well as their binding affinity to proteins, cellular uptake, and subsequent biological responses, which is critically important for utilization of MWCNTs in medicine.

Surface modification of MWCNTs has the potential to alter their surface charge and dispersability. We previously demonstrated that the carboxylated MWCNTs had high negative zeta potential and increased stability in water [34], which is similar to our current result. In this study, we further found that base washing had no impact on the size and zeta potential of F-MWCNTs but increased the solubility of F-MWCNTs in water. Wu et al. reported similar results in which base washing dramatically increased carboxylic groups on the surface of F-MWCNTS but no significant alterations in zeta potential, particle size, and colloidal stability were observed [30]. In contrast, Heister et al. reported that base washing impaired dispersion stability [28]. The varied results from those two studies are likely due to different treatment methods of synthesizing F-MWCNTs. 


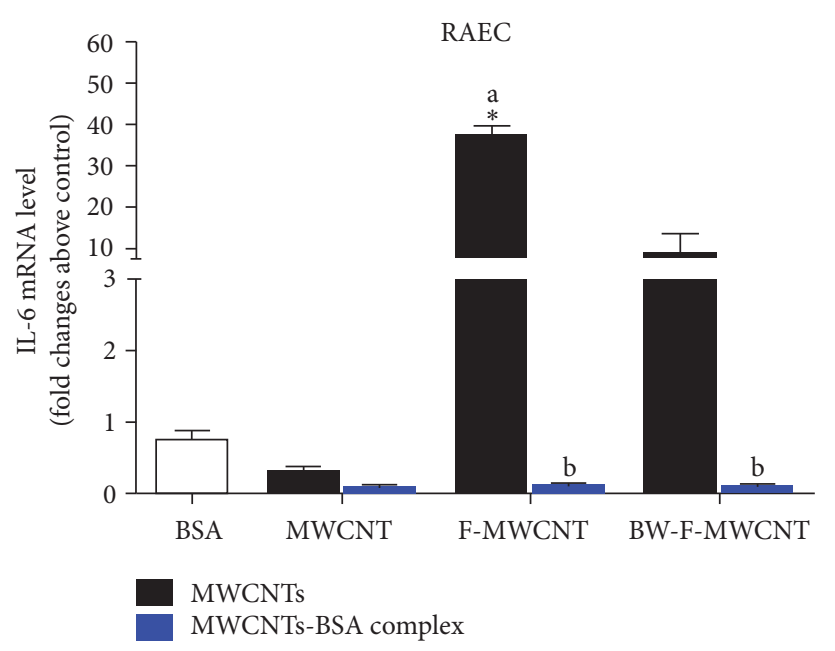

(a)

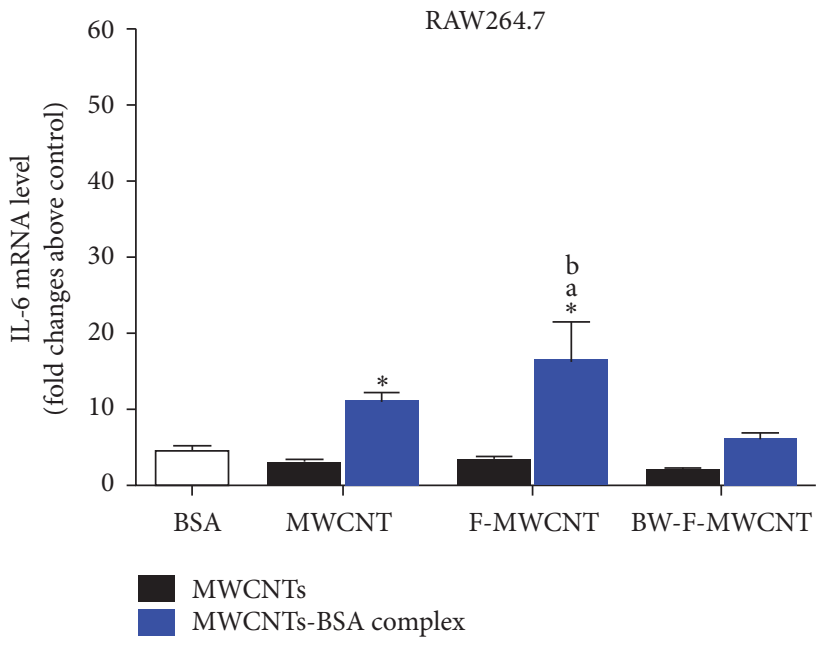

(c)

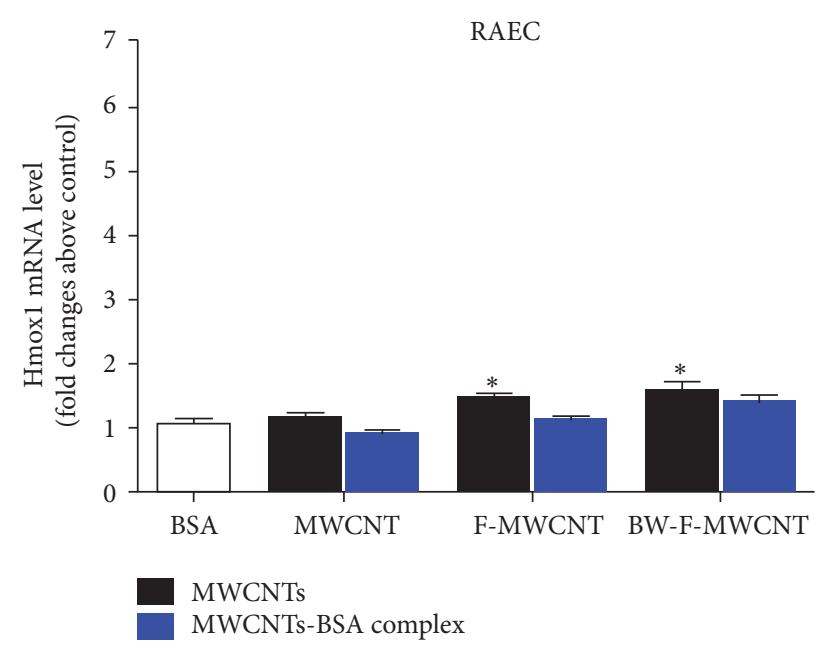

(b)

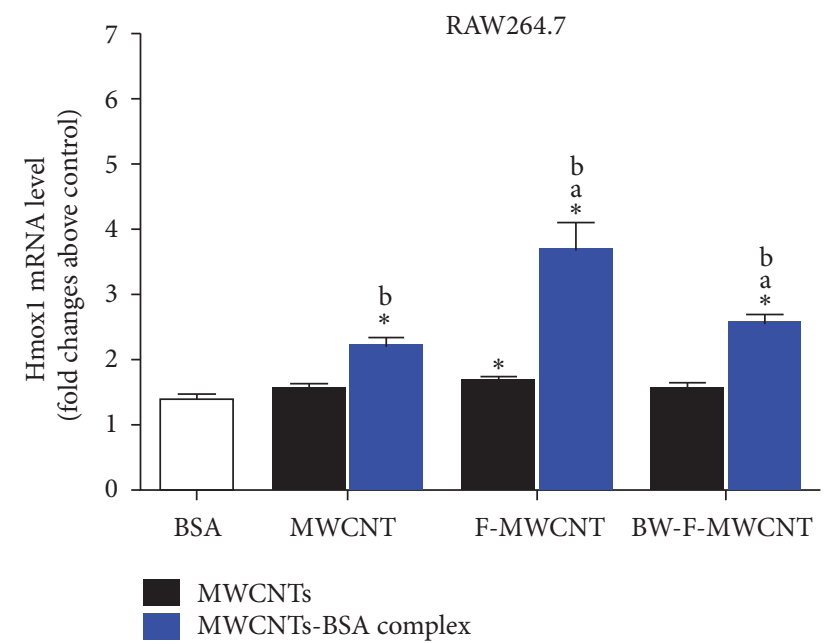

(d)

FIGURE 4: Changes in gene expression in RAEC or RAW264.7 cells. (a) The level of IL-6 mRNA in RAEC cells, (b) the level of Hmox1 mRNA in RAEC cells, (c) the level of IL-6 mRNA in RAW264.7 cells, and (d) the level of Hmoxl mRNA in RAW264.7 cells. ${ }^{*} p<0.05$, compared to the control; ${ }^{\mathrm{a}} p<0.05$, compared to the BSA-treated group; ${ }^{\mathrm{b}} p<0.05$, comparison between MWCNTs with and that without BSA coating.

Despite the contradictory differences, those studies highlight the importance of base washing on the surface properties of carboxylated MWCNTs.

While the formation of a protein corona on nanoparticles has been well known upon their contact with biological fluids, such as blood, plasma, or interstitial fluid $[7,8]$, there is still a lack of understanding of mechanisms underlining the interaction between proteins and nanoparticles, including the dependence of nanoparticles ability to absorb the proteins on their surface properties, as well as the potential influence of the protein binding on surface properties. We employed bovine serum albumin (BSA) as a model protein to study the interaction between BSA and MWCNTs before and after carboxylation and base washing. Our work showed that carboxylation of MWCNTs enhanced their ability to bind BSA as compared to pristine MWCNTs, which is consistent with the others $[35,36]$. We further demonstrated that base washing dramatically enhanced the ability of carboxylated
MWCNTs to bind BSA. This implies that impurities on the F-MWCNTs surface prevent the adsorption of proteins. Similarly, Du et al. reported that adsorption of BSA on MWCNTs was dependent on the surface area, functional groups, and hydrophobicity [37]. At the same time $\mathrm{Mu}$ et al. found that functionalized MWCNT with a larger diameter $(\sim 40 \mathrm{~nm})$ generally exhibited stronger protein binding compared to those with a smaller diameter $(\sim 10 \mathrm{~nm})$, suggesting that the electrostatic and stereochemical nature of both nanotubes and protein govern nanotube/protein binding [36]. In this work, we also found that BSA binding had no influence on the size and zeta potential of F-MWCNTs and BW-FMWCNTs in water, possibly due to monolayer adsorption of BSA on the surface [38]. However, we did find that BSA binding decreased the hydrodynamic size of pristine MWCNTs, which is due to the steric and colloidal stability provided by the surface coating $[38,39]$. 
In this study, we demonstrated that carboxylation and base washing increased cellular uptake of F-MWCNTs and BW-F-MWCNTs compared to pristine MWCNTs, possibly due to increased dispersion. We also found that BSA binding increased the uptake of pristine MWCNTs in RAW264.7 cells. Similarly, Holt et al. found that purified SWCNTs with less solubility was minimally internalized by human mesenchymal stem cells (hMSC) and HeLa cells, but BSA coating could effectively disperse SWCNTs and enhance their uptake [40]. Wang et al. also found that BSA could act as an effective dispersant for as-prepared MWCNTs and purified MWCNTs in various tissue culture media and thought that better nanotube dispersal could increase the local dosimetry resulting in increased contact of nanotube with cellular membrane [39]. Taken together, it seems that the better dispersion can enhance the cellular uptake by increasing due to improved cellular dosimetry.

The toxicity associated with carbon nanotubes is a major concern for their use in biomedical applications. For example, we have previously reported that MWCNTs with a length of $10-100 \mu \mathrm{m}$ impaired pulmonary function [41] and induced severe cardiac ischemic/reperfusion injury after pulmonary instillation [42]. Similar results on MWCNT toxicity have been reported [43-46]. However, it is being recognized that toxicity induced by carbon nanotubes is highly dependent on their length and functionalization. Kam et al. reported that carbon nanotubes with a length shorter than $2 \mu \mathrm{m}$ exhibited no toxicity to various cell types including human promyelocytic leukemia (HL60) and human T cells (Jurkat) [47]. Further, the toxicity of carbon nanotubes could be reduced by chemical functionalization, such as carboxylation [34, 48, 49], octyl functionalization [50], and PEGylation [51]. In addition, BSA binding to carbon nanotubes was also found to effectively reduce the toxicity of pristine nanotubes [40]. Consistent with the studies above, our current results demonstrated that pristine MWCNTs, carboxylated MWCNTs, and base-washed carboxylated MWCNTs did not affect viability of endothelial and macrophage cells. Based on previous literature, we conclude that the absence of toxicity is due to the shorter length of the MWCNTs utilized and increased dispersion due to carboxylation.

Interleukin-6 (IL-6) is a cytokine involved in immune regulation, hematopoiesis, inflammation, and oncogenesis [52]. Recent studies have demonstrated that treatment with carboxylated carbon nanotubes increased IL- 6 production [49, 53-55]. Similarly, we found that pristine MWCNTs, carboxylated MWCNT, and base-washed MWCNTs remarkably increased the level of IL- 6 mRNA in RAEC cells. Moreover, we found that BSA binding completely inhibited IL-6 expression induced by uncoated MWCNTs, suggesting that BSA binding has an ability to modulate the bioactivity of carbon nanotubes. On the other hand, we did not find an increase in IL-6 expression in RAW264.7 cells, possibly because we used much shorter MWCNTs $(<1 \mu \mathrm{m})$ than those Zhang et al. used (5-15 $\mu \mathrm{m})$. But we did find that BSA-coated MWCNTs increased IL-6 expression compared to uncoated ones, and the mechanism of cellular variability observed remains unknown.
Induction of oxidative stress is another concern over the safe use of carbon nanotubes $[46,56]$. In this work, we examined expression of Heme oxygenase 1 (Hmoxl), an oxidative stress inducible gene, in RAEC cells and RAW264.7 cells. Sarkar et al. found that SWCNTs induced Hmoxl expression in BJ Foreskin cells, which is possibly a protective adaptation to the oxidative stress induced by SWCNTs [57]. Cao et al. found that there was increased expression of Hmoxl in the lungs of MWCNT-exposed mice but not monocytic THP-1 cells [58]. Al Faraj et al. did not find the expression of Hmoxl in mice injected with single-walled carbon nanotubes [59]. These studies show the complexity of oxidative stress in terms of Hmoxl expression. Interestingly, we found that carboxylated MWCNT (F-MWCNTs) induced Hmoxl expression in both RAEC cells and RAW264.7 cells, and base washing did not alter Hmoxl expression. We also found that BSA binding inhibited the induction of Hmoxl in RAEC cells but enhanced Hmoxl expression in RAW264.7 cells. These results suggest that the induction of Hmoxl induced by MWCNTs could be influenced by protein binding in a cell type dependent way.

\section{Conclusions}

Taken together, our work demonstrated that carboxylation of carbon nanotubes increased their capability to bind more BSA, and base washing enhanced their binding capacity. We also found that carboxylation and base washing of MWCNTs altered gene expression in a cell type dependent manner following exposure and was further influenced by BSA binding. These findings are important as many toxicological studies of nanomaterials often only focus on one cell type and do not account for the influence of surface modification and formation of a protein corona. Overall, these findings improve our understanding of the mechanisms responsible for interaction of MWCNTs and proteins and provide insight for the strategic design of carbon nanotube-based drug delivery systems with minimal toxicity and enhanced specificity and efficacy of proteins or drugs.

\section{Competing Interests}

The authors declare that they have no competing interests.

\section{Acknowledgments}

This work was supported by grants from the National Institutes of Health (R01 ES019311, R01 ES023209, and R03 ES023036).

\section{References}

[1] K. Kostarelos, A. Bianco, and M. Prato, "Promises, facts and challenges for carbon nanotubes in imaging and therapeutics," Nature Nanotechnology, vol. 4, no. 10, pp. 627-633, 2009.

[2] M. F. L. De Volder, S. H. Tawfick, R. H. Baughman, and A. J. Hart, "Carbon nanotubes: present and future commercial applications," Science, vol. 339, no. 6119, pp. 535-539, 2013. 
[3] N. Saito, H. Haniu, Y. Usui et al., "Safe clinical use of carbon nanotubes as innovative biomaterials," Chemical Reviews, vol. 114, no. 11, pp. 6040-6079, 2014.

[4] E. Heister, E. W. Brunner, G. R. Dieckmann, I. Jurewicz, and A. B. Dalton, "Are carbon nanotubes a natural solution? applications in biology and medicine," ACS Applied Materials and Interfaces, vol. 5, no. 6, pp. 1870-1891, 2013.

[5] Q. Mu, G. Jiang, L. Chen et al., "Chemical basis of interactions between engineered nanoparticles and biological systems," Chemical Reviews, vol. 114, no. 15, pp. 7740-7781, 2014.

[6] Y. Liu, Y. Zhao, B. Sun, and C. Chen, "Understanding the toxicity of carbon nanotubes," Accounts of Chemical Research, vol. 46, no. 3, pp. 702-713, 2013.

[7] A. E. Nel, L. Mädler, D. Velegol et al., "Understanding biophysicochemical interactions at the nano-bio interface," Nature Materials, vol. 8, no. 7, pp. 543-557, 2009.

[8] I. Lynch and K. A. Dawson, "Protein-nanoparticle interactions," Nano Today, vol. 3, no. 1-2, pp. 40-47, 2008.

[9] X. Zhao, R. Liu, Z. Chi, Y. Teng, and P. Qin, "New insights into the behavior of bovine serum albumin adsorbed onto carbon nanotubes: comprehensive spectroscopic studies," Journal of Physical Chemistry B, vol. 114, no. 16, pp. 5625-5631, 2010.

[10] R. Podila, P. Vedantam, P. C. Ke, J. M. Brown, and A. M. Rao, "Evidence for charge-transfer-induced conformational changes in carbon nanostructure-protein corona," Journal of Physical Chemistry C, vol. 116, no. 41, pp. 22098-22103, 2012.

[11] S. Liu, Y. Sui, K. Guo, Z. Yin, and X. Gao, "Spectroscopic study on the interaction of pristine C60 and serum albumins in solution," Nanoscale Research Letters, vol. 7, no. 1, p. 433, 2012.

[12] C. Ge, J. Du, L. Zhao et al., "Binding of blood proteins to carbon nanotubes reduces cytotoxicity," Proceedings of the National Academy of Sciences of the United States of America, vol. 108, no. 41, pp. 16968-16973, 2011.

[13] D.-H. Tsai, F. W. DelRio, A. M. Keene et al., "Adsorption and conformation of serum albumin protein on gold nanoparticles investigated using dimensional measurements and in situ spectroscopic methods," Langmuir, vol. 27, no. 6, pp. 2464-2477, 2011.

[14] N. Wangoo, C. R. Suri, and G. Shekhawat, "Interaction of gold nanoparticles with protein: a spectroscopic study to monitor protein conformational changes," Applied Physics Letters, vol. 92, no. 13, Article ID 133104, 2008.

[15] S. H. Brewer, W. R. Glomm, M. C. Johnson, M. K. Knag, and S. Franzen, "Probing BSA binding to citrate-coated gold nanoparticles and surfaces," Langmuir, vol. 21, no. 20, pp. 93039307, 2005.

[16] K. Rezwan, L. P. Meier, M. Rezwan, J. Vörös, M. Textor, and L. J. Gauckler, "Bovine serum albumin adsorption onto colloidal $\mathrm{Al}_{2} \mathrm{O}_{3}$ particles: a new model based on zeta potential and UVVis measurements," Langmuir, vol. 20, no. 23, pp. 10055-10061, 2004.

[17] M. Bardhan, G. Mandal, and T. Ganguly, "Steady state, time resolved, and circular dichroism spectroscopic studies to reveal the nature of interactions of zinc oxide nanoparticles with transport protein bovine serum albumin and to monitor the possible protein conformational changes," Journal of Applied Physics, vol. 106, no. 3, Article ID 034701, 2009.

[18] A. Kathiravan, G. Paramaguru, and R. Renganathan, "Study on the binding of colloidal zinc oxide nanoparticles with bovine serum albumin," Journal of Molecular Structure, vol. 934, no. 13, pp. 129-137, 2009.
[19] B. I. Kharisov, O. V. Kharissova, H. L. Gutierrez, and U. O. Méndez, "Recent advances on the soluble carbon nanotubes," Industrial and Engineering Chemistry Research, vol. 48, no. 2, pp. 572-590, 2009.

[20] N. Karousis, N. Tagmatarchis, and D. Tasis, "Current progress on the chemical modification of carbon nanotubes," Chemical Reviews, vol. 110, no. 9, pp. 5366-5397, 2010.

[21] Y. Wang, Z. Iqbal, and S. Mitra, "Rapidly functionalized, waterdispersed carbon nanotubes at high concentration," Journal of the American Chemical Society, vol. 128, no. 1, pp. 95-99, 2006.

[22] Y. Chen and S. Mitra, "Fast microwave-assisted purification, functionalization and dispersion of multi-walled carbon nanotubes," Journal of Nanoscience and Nanotechnology, vol. 8, no. 11, pp. 5770-5775, 2008.

[23] J. H. Shannahan, J. M. Brown, R. Chen et al., "Comparison of nanotube-protein corona composition in cell culture media," Small, vol. 9, no. 12, pp. 2171-2181, 2013.

[24] C. G. Salzmann, S. A. Llewellyn, G. Tobias, M. A. H. Ward, Y. Huh, and M. L. H. Green, "The role of carboxylated carbonaceous fragments in the functionalization and spectroscopy of a single-walled carbon-nanotube material," Advanced Materials, vol. 19, no. 6, pp. 883-887, 2007.

[25] R. Verdejo, S. Lamoriniere, B. Cottam, A. Bismarck, and M. Shaffer, "Removal of oxidation debris from multi-walled carbon nanotubes," Chemical Communications, no. 5, pp. 513-515, 2007.

[26] L. Shao, G. Tobias, C. G. Salzmann et al., "Removal of amorphous carbon for the efficient sidewall functionalisation of single-walled carbon nanotubes," Chemical Communications, no. 47, pp. 5090-5092, 2007.

[27] S. Fogden, R. Verdejo, B. Cottam, and M. Shaffer, "Purification of single walled carbon nanotubes: the problem with oxidation debris," Chemical Physics Letters, vol. 460, no. 1-3, pp. 162-167, 2008.

[28] E. Heister, C. Lamprecht, V. Neves et al., "Higher dispersion efficacy of functionalized carbon nanotubes in chemical and biological environments," ACS Nano, vol. 4, no. 5, pp. 26152626, 2010.

[29] D. Stéfani, A. J. Paula, B. G. Vaz et al., "Structural and proactive safety aspects of oxidation debris from multiwalled carbon nanotubes," Journal of Hazardous Materials, vol. 189, no. 1-2, pp. 391-396, 2011.

[30] Z. Wu, R. F. Hamilton Jr., Z. Wang, A. Holian, and S. Mitra, "Oxidation debris in microwave functionalized carbon nanotubes: chemical and biological effects," Carbon, vol. 68, pp. 678-686, 2014.

[31] Y. H. Chen, Z. Iqbal, and S. Mitra, "Microwave-induced controlled purification of single-walled carbon nanotubes without sidewall functionalization," Advanced Functional Materials, vol. 17, no. 18, pp. 3946-3951, 2007.

[32] Y. Ibuki and T. Toyooka, "Nanoparticle uptake measured by flow cytometry," Methods in Molecular Biology, vol. 926, pp. 157-166, 2012.

[33] T. Xia, R. F. Hamilton Jr., J. C. Bonner et al., "Interlaboratory evaluation of in vitro cytotoxicity and inflammatory responses to engineered nanomaterials: the NIEHS Nano GO Consortium," Environmental Health Perspectives, vol. 121, no. 6, pp. 683-690, 2013.

[34] R. F. Hamilton Jr., C. Xiang, M. Li et al., "Purification and sidewall functionalization of multiwalled carbon nanotubes and resulting bioactivity in two macrophage models," Inhalation Toxicology, vol. 25, no. 4, pp. 199-210, 2013. 
[35] B. Kim and W. M. Sigmund, "Functionalized multiwall carbon nanotube/gold nanoparticle composites," Langmuir, vol. 20, no. 19, pp. 8239-8242, 2004.

[36] Q. Mu, W. Liu, Y. Xing et al., "Protein binding by functionalized multiwalled carbon nanotubes is governed by the surface chemistry of both parties and the nanotube diameter," Journal of Physical Chemistry C, vol. 112, no. 9, pp. 3300-3307, 2008.

[37] P. Du, J. Zhao, and B. S. Xing, "Adsorption of bovine serum albumin on functionalized carbon nanotubes," in Proceedings of the 245rd American Chemical Society (ACS) National Meeting, vol. 245 of Abstracts of Papers of the American Chemical Society, New Orleans, La, USA, 2013.

[38] P. Du, J. Zhao, H. Mashayekhi, and B. Xing, "Adsorption of bovine serum albumin and lysozyme on functionalized carbon nanotubes," Journal of Physical Chemistry C, vol. 118, no. 38, pp. 22249-22257, 2014.

[39] X. Wang, T. Xia, S. A. Ntim et al., "Quantitative techniques for assessing and controlling the dispersion and biological effects of multiwalled carbon nanotubes in mammalian tissue culture cells," ACS Nano, vol. 4, no. 12, pp. 7241-7252, 2010.

[40] B. D. Holt, K. N. Dahl, and M. F. Islam, "Quantification of uptake and localization of bovine serum albumin-stabilized single-wall carbon nanotubes in different human cell types," Small, vol. 7, no. 16, pp. 2348-2355, 2011.

[41] X. Wang, P. Katwa, R. Podila et al., "Multi-walled carbon nanotube instillation impairs pulmonary function in C57BL/6 mice," Particle and Fibre Toxicology, vol. 8, article 24, 2011.

[42] R. N. Urankar, R. M. Lust, E. Mann et al., "Expansion of cardiac ischemia/reperfusion injury after instillation of three forms of multi-walled carbon nanotubes," Particle and Fibre Toxicology, vol. 9, article 38, 2012.

[43] R. Chen, L. Zhang, C. Ge et al., "Subchronic toxicity and cardiovascular responses in spontaneously hypertensive rats after exposure to multiwalled carbon nanotubes by intratracheal instillation," Chemical Research in Toxicology, vol. 28, no. 3, pp. 440-450, 2015.

[44] C. A. Poland, R. Duffin, I. Kinloch et al., "Carbon nanotubes introduced into the abdominal cavity of mice show asbestoslike pathogenicity in a pilot study," Nature Nanotechnology, vol. 3, no. 7, pp. 423-428, 2008.

[45] J. P. Ryman-Rasmussen, E. W. Tewksbury, O. R. Moss, M. F. Cesta, B. A. Wong, and J. C. Bonner, "Inhaled multiwalled carbon nanotubes potentiate airway fibrosis in murine allergic asthma," American Journal of Respiratory Cell and Molecular Biology, vol. 40, no. 3, pp. 349-358, 2009.

[46] K. Donaldson, R. Aitken, L. Tran et al., "Carbon nanotubes: a review of their properties in relation to pulmonary toxicology and workplace safety," Toxicological Sciences, vol. 92, no. 1, pp. $5-22,2006$.

[47] N. W. S. Kam, T. C. Jessop, P. A. Wender, and H. Dai, "Nanotube molecular transporters: internalization of carbon nanotube-protein conjugates into mammalian cells," Journal of the American Chemical Society, vol. 126, no. 22, pp. 6850-6851, 2004.

[48] Z. Liu, X. Dong, L. Song et al., "Carboxylation of multiwalled carbon nanotube enhanced its biocompatibility with L02 cells through decreased activation of mitochondrial apoptotic pathway," Journal of Biomedical Materials Research - art A, vol. 102, no. 3, pp. 665-673, 2014.

[49] S. Jain, V. S. Thakare, M. Das et al., "Toxicity of multiwalled carbon nanotubes with end defects critically depends on their functionalization density," Chemical Research in Toxicology, vol. 24, no. 11, pp. 2028-2039, 2011.

[50] H. Ali-Boucetta, A. Nunes, R. Sainz et al., "Asbestos-like pathogenicity of long carbon nanotubes alleviated by chemical functionalization," Angewandte Chemie-International Edition, vol. 52, no. 8, pp. 2274-2278, 2013.

[51] Y. Zhang, Y. Xu, Z. Li et al., "Mechanistic toxicity evaluation of uncoated and PEGylated single-walled carbon nanotubes in neuronal PC12 cells," ACS Nano, vol. 5, no. 9, pp. 7020-7033, 2011.

[52] T. Kishimoto, "IL-6: from its discovery to clinical applications," International Immunology, vol. 22, no. 5, pp. 347-352, 2010.

[53] L. W. Zhang, L. Zeng, A. R. Barron, and N. A. Monteiro-Riviere, "Biological interactions of functionalized single-wall carbon nanotubes in human epidermal keratinocytes," International Journal of Toxicology, vol. 26, no. 2, pp. 103-113, 2007.

[54] S. Ye, H. Zhang, Y. Wang, F. Jiao, C. Lin, and Q. Zhang, "Carboxylated single-walled carbon nanotubes induce an inflammatory response in human primary monocytes through oxidative stress and NF- $\kappa$ B activation," Journal of Nanoparticle Research, vol. 13, no. 9, pp. 4239-4252, 2011.

[55] T. Zhang, M. Tang, L. Kong et al., "Comparison of cytotoxic and inflammatory responses of pristine and functionalized multiwalled carbon nanotubes in RAW 264.7 mouse macrophages," Journal of Hazardous Materials, vol. 219-220, pp. 203-212, 2012.

[56] A. A. Shvedova, A. Pietroiusti, B. Fadeel, and V. E. Kagan, "Mechanisms of carbon nanotube-induced toxicity: focus on oxidative stress," Toxicology and Applied Pharmacology, vol. 261, no. 2, pp. 121-133, 2012.

[57] S. Sarkar, C. Sharma, R. Yog et al., "Analysis of stress responsive genes induced by single-walled carbon nanotubes in BJ Foreskin cells," Journal of Nanoscience and Nanotechnology, vol. 7, no. 2, pp. 584-592, 2007.

[58] Y. Cao, N. R. Jacobsen, P. H. Danielsen et al., "Vascular effects of multiwalled carbon nanotubes in dyslipidemic apoE-/- mice and cultured endothelial cells," Toxicological Sciences, vol. 138, no. 1, pp. 104-116, 2014.

[59] A. Al Faraj, F. Fauvelle, N. Luciani et al., "In vivo biodistribution and biological impact of injected carbon nanotubes using magnetic resonance techniques," Journal of International Journal of Nanomedicine, vol. 6, no. 2, pp. 351-361, 2011. 

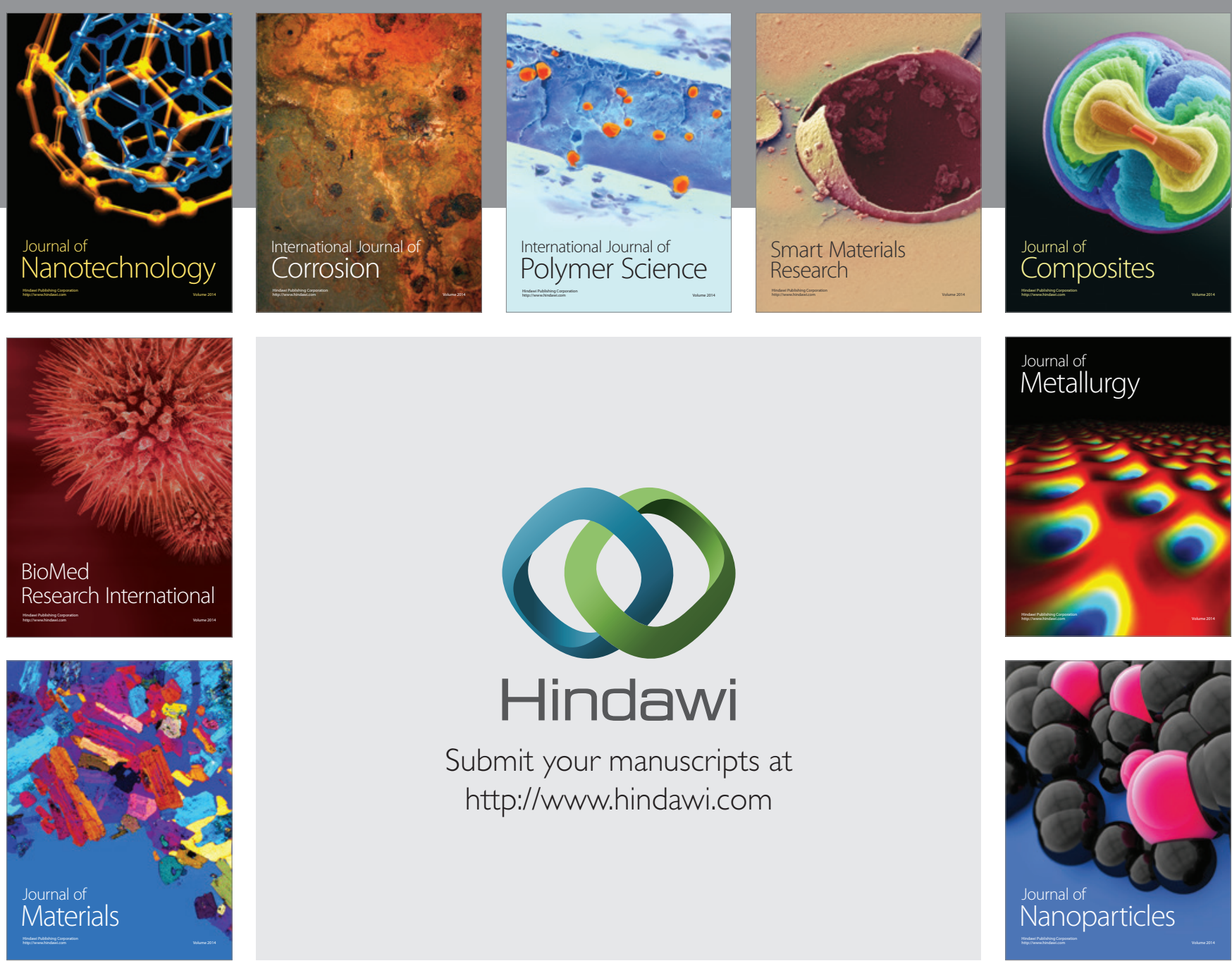

\section{Hindawi}

Submit your manuscripts at

http://www.hindawi.com

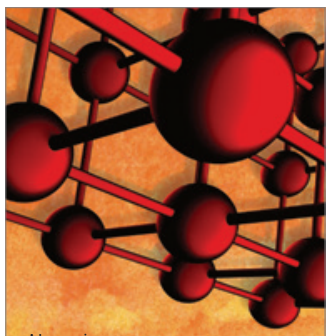

Materials Science and Engineering
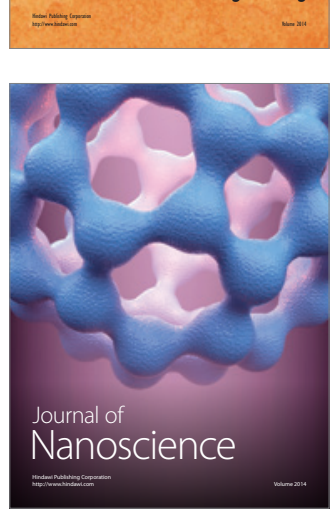
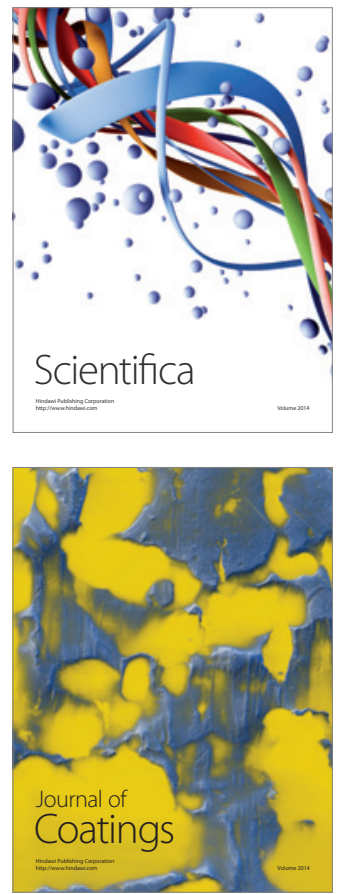
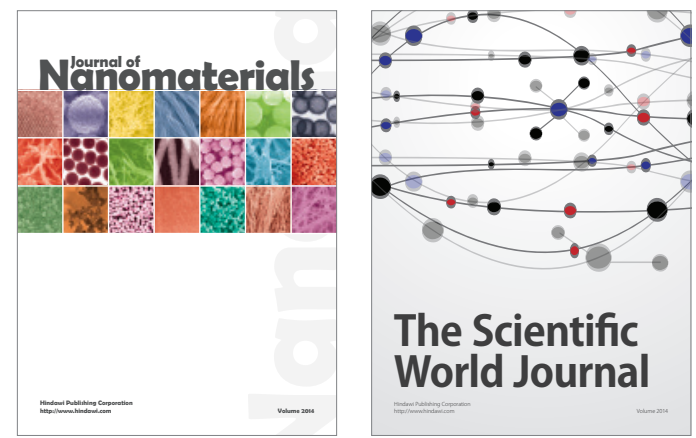

The Scientific World Journal
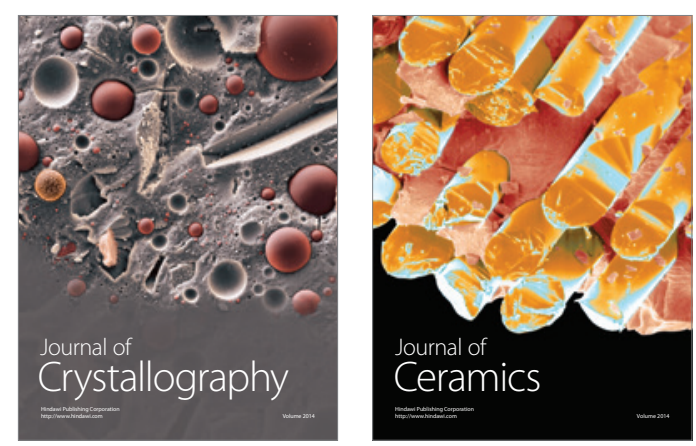
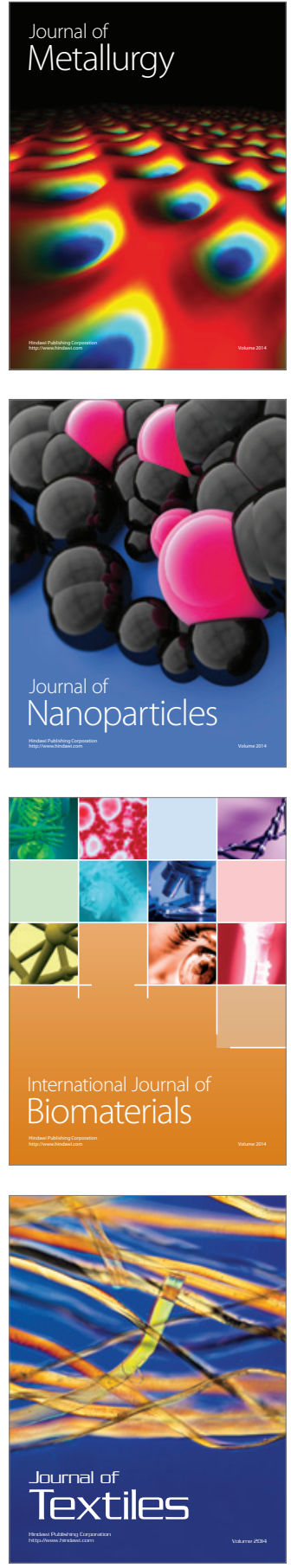